\title{
FORMAS DE FUNDAMENTAR LA UNIDAD POLÍTICA. La recepción de Aristóteles por Tomás de Aquino FRENTE A SAN AgUSTÍN Y AL AgUSTINISMO
}

\author{
Hugo Herrera Arellano*
}

RESUMEN: En el presente artículo se busca abordar una cuestión filosófico-política central, altamente discutida: el problema del fundamento o justificación del Estado. El Estado (o unidad política) no realiza sus tareas amparado solo en la persuasión y el afecto; medio esencial de su acción es también la fuerza. La pregunta por la justificación del Estado admite dos respuestas: la que niega la posibilidad de justificación (anarquismo y marxismo) y la que admite la posibilidad de justificación. Dentro de esta última se puede distinguir una justificación "negativa", que muestra cómo el Estado puede superar la situación de desorden preestatal, y una justificación "positiva", que marca el énfasis en las bondades de la vida comunitaria que se alcanza en la polis o unidad política. En el artículo se muestra la insuficiencia que exhiben la negación anarquista y marxista del Estado. Luego se abordan, en lo fundamental, los dos modos de justificación en autores altamente relevantes para la bistoria de la filosofía política: Aristóteles, Agustín de Hipona, Tomás de Aquino y Kant. Se intenta mostrar, en definitiva, que, bien entendida, la fundamentación "positiva" de la unidad política permite superar problemas que la "negativa" deja pendientes.

Palabras clave: Estado - Fundamento - Justificación - Aristóteles - Tomás de Aquino - Agustín de Hipona - Kant.

\section{FORMS TO ESTABLISH THE POLITICAL UNITY The reception of Aristotle by Thomas Aquinas as opposed to Saint Augustine and Augustinism}

ABSTRACT: This article seeks to approach a bighly discussed, central Philosopbical-Political issue: the problem of the basis or the justification of the State. The State -or political unity-does not carry out tasks supported only in persuasion and affection; the force is also an esential means for its action. The question about the justification of the State allows two answers:

Abogado. Doctor en Filosofía por la U. de Würzburg. Profesor en la Universidad de los Andes. Correo electrónico hherrera@uandes.cl

Artículo recibido el 28 de diciembre de 2005. Aprobado por el Comité Editorial el 10 de mayo de 2006. 
the one that denies the possibility of justification (anarchism and marxism) and the one that accepts the possibility of justification. Among the last one it's possible to distinguish a "negative" justification, that shows bow can the State overcome the situation of prestate disorder, and a "positive" justification, that emphasizes the goodness of community life that is reached in the polis or political unity. The article shows the insufficiency exposed by the anarchist and marxist denial of the State. Later the two modes of justification are basically approached, within highly relevant authors for the bistory of political philosophy: Aristotle, Augustine of Hippo, Thomas Aquinas, and Kant. In short, the article attempts to show that, well understood, the "positive" basis of the political unity allows the overcoming of those problems that the "negative" (basis) leaves unresolved.

KEY wORDS: State - Basis - Justification - Aristotle - Thomas Aquinas - Augustine of Hippo - Kant.

SUMARIO: 1.- Plausibilidad de la pregunta por la justificación del Estado o unidad política. 2.- Dos tipos de fundamentación. 3.- La fundamentación "negativa" de Agustín de Hipona. 4.- El pensamiento político medieval antes de Tomás de Aquino. 5. - La complementación tomista de la fundamentación negativa de la unidad política y las posibilidades de fortalecimiento de esa unidad política que de ahí se siguen. 6.- Justificación "positiva" y libertad.

\section{Plausibilidad de la pregunta por la justificación del ESTADO O UNIDAD POLÍtICA ${ }^{1}$}

La cuestión del fundamento o justificación del Estado es problemática. Si se tiene presente que el Estado concreto está provisto de mecanismos para actuar violentamente, que puede oprimir y matar, si la historia nos provee de ejemplos de Estados bajo los cuales se padeció opresión y miseria, cabe preguntarse ¿por qué razón aceptarlo?

La pregunta por la justificación de la unidad política o Estado no solo ha sido respondida negativamente mediante alzamientos y revoluciones, es posible citar dos ejemplos manifiestos de posiciones teóricas que niegan que existan argumentos capaces de llegar a justificar de-

\footnotetext{
Aquí conviene hacer una aclaración: somos conscientes de la discusión que ha generado el empleo universalizante de la expresión "Estado". En este artículo se emplean como sinónimos los términos Estado y unidad política, no obstante que, para evitar imprecisiones, hacemos la salvedad: Estado no es entendido como la forma moderna de unidad política, racionalizada, asentada sobre un territorio con fronteras estables detalladamente fijadas, con burocracia y ejército profesionales. La palabra Estado es empleada en un sentido amplio, de tal modo que abarca a toda unidad política, tanto a la polis y al reino medieval, como al Estado moderno.
} 
finitivamente la aceptación del Estado: el marxismo y el anarquismo. Como se sabe, para Marx el Estado es expresión del orden de propiedad privada, un instrumento en las manos de la burguesía para la defensa de esa propiedad. En el Manifiesto Comunista es calificado como:

un mero comité para la administración de los negocios comunes de la clase burguesa $^{2}$.

Este orden de propiedad enajena al ser humano y debe ser, por tanto, superado.

La abolición positiva de la propiedad privada [...] es la abolición positiva de toda enajenación, y el regreso del ser bumano desde la religión, la familia, el Estado, etc., hacia su existir bumano, es decir, social ${ }^{3}$.

Para las corrientes anarquistas el Estado y el gobierno deben desaparecer.

El anarquista ve en el Estado el Moloc omnipresente del sometimiento bumano [...]. Fin del Anarquismo es la sociedad libre de dominio ${ }^{4}$.

El Estado sería expresión de mero poderío e impediría el despliegue de lo humano. Por eso debe ser abolido.

Ambas posiciones vuelven la cuestión de la fundamentación del Estado no solo atendible, sino altamente relevante para quienes vivimos, precisamente, dentro del Estado. ¿De qué maneras es posible justificar al Estado?

\section{Dos TIPOS DE FUNDAMENTACIÓN}

La unidad política o Estado puede ser, hasta donde vemos, fundamentada de dos maneras diversas, que se vinculan históricamente a los nombres de Agustín de Hipona y Aristóteles. Es, no obstante, Tomás de Aquino quien se encargará de rescatar el pensamiento del Estagirita

2 Karl Marx/Friedrich ENGELS, Werke (ed. por Hans-Joachim Lieber y otros), Stuttgart/ Darmstadt 1962, Tomo II, pp, 819 s.

3 Op. cit. Tomo I, p. 595.

4 Peter Lösche, Anarchismus. Darmstadt 1977, pp. 17 s.; cf. Hans Diefenbacher, Anarchismus - die verlorene Utopie?, en: H. Diefrenbacher (ed.): Anarchismus. Zur Geschichte und Idee der berrschaftsfreien Gesellschaft. Darmstadt 1996, pp. 10 s.; Michael BaKunin, Prinzipien und Organisation der Internationalen Revolutionären Gesellschaft, en: Gesammelte Werke. Berlín 1975, Tomo III, pp. 7-66. 
para la Cristiandad y Occidente ${ }^{5}$. Estas maneras admiten diversos énfasis y matices; sin embargo, siempre que se pretende justificar la presencia de un poder político, se emplea alguna de estas maneras o las dos en conjunto.

La primera consiste en mostrar cómo el Estado u orden político contribuye al despliegue humano, a volverlo mejor, virtuoso o feliz. Este despliegue tiene lugar porque el orden político se encuentra en una relación de cierta adecuación, más o menos estrecha, con la estructura humana. Solo en la medida en que el Estado "esencialmente" o "según su estructura" y no por mera casualidad es capaz de desplegar aspectos relevantes del ser humano, es que resulta posible justificarlo como posibilitador de ese despliegue. De lo contrario, si se sostiene que el despliegue humano es logrado solo accidentalmente, por casualidad, por la conjunción espontánea y efímera de factores variables, entonces, este tipo de justificación del Estado no será ya posible.

Una segunda manera de justificar a la unidad política consiste en mostrar los daños o perjuicios que la instauración de un orden político evita. El orden político es un orden de paz armada que se establece para superar la debilidad y problematicidad humanas. Ambas admiten diversas maneras de ser entendidas. Pueden ser vistas como expresión de la maldad humana, producto del pecado original, o simplemente como carencia de lo corporalmente necesario y tendencia animal al empleo de la violencia, como consecuencia (debilidad) y afán de vulnerar la ley de Dios (problematicidad) o como simple incertidumbre jurídica propia de la situación en que, por falta de un poder público superior, impera el "derecho" del más fuerte. Lo relevante es que aquí el Estado representa el orden de paz armado por medio del cual se impiden los abusos de particulares, la muerte violenta a manos de terceros, en definitiva una situación contraria a la razón práctica: la inexistencia de un orden cierto de trato entre humanos. Así también, por medio del Estado, se puede asegurar lo necesario para la vida.

\section{La fundamentación "Negativa” de Agustín de Hipona ${ }^{6}$}

En este parágrafo no pretendemos emprender un análisis detenido de la teoría política agustiniana, sino simplemente fijar su posición en

5 No obstante que hay un comentario de la Política de Aristóteles escrito por Alberto Magno, este comentario tiene un carácter marcadamente literal. En Tomás de Aquino, en cambio, la literalidad cede paso a la interpretación. Esta interpretación será altamente relevante para la historia de Occidente.

6 Sobre este tema: D. Sternberger: "Der alte Streit um den Ursprung der Herrschaft" (1977), en: D. STERNBerger, Scbriften III. Frankfurt a. M. 1980, especialmente: pp. 23 
la cuestión de la fundamentación del poder político, a partir de textos relevantes.

Para Agustín, la política y el orden político tienden a ser concebidos como expresiones de la maldad y de la necesidad humana. Porque el hombre es imperfecto, como consecuencia del pecado, y porque requiere de ciertos bienes para subsistir, es que necesita organizarse políticamente: para establecer la paz y una modo de vivir que supere la situación de carencia.

En el capítulo 17 del libro XIX indica Agustín que quienes viven en la fe, esto es, quienes componen la "ciudad de Dios peregrina", requieren de la paz terrena "por necesidad, hasta que pase la mortalidad, que precisa de tal paz. Y por eso, mientras que ella [la ciudad de Dios peregrina] está como viajero cautivo en la ciudad terrena, habiendo recibido ya la promesa de su redención y el don espiritual como prenda de ella, no duda en obedecer las leyes de la ciudad terrenal que reglamentan las cosas necesarias y el mandamiento de la vida mortal" 7 . En el capítulo 16 del mismo libro señala que en la "casa celestial" no será "necesario mandar a los hombres, porque en la inmortalidad no será preciso subvenir a necesidad alguna".

El origen más profundo de la necesidad y de la necesidad de gobierno hay que buscarlo, sin embargo, en la maldad humana, derivada del pecado. Dios ha querido que los hombres no se dominasen. Los creó libres. No obstante, el pecado y la iniquidad han llevado al hombre a la necesidad de instaurar un poder político. La "iniquidad" es el origen del "principado" y de la "potestad humana". Con el fin del mal, en el reino de los cielos, "el principado y la potestad humana" deberán desaparecer ${ }^{8}$.

La política, tal como la comprende Agustín, no parece constituir un ámbito propio, pues, por una parte, no se la distingue claramente de una sociedad establecida para superar necesidades materiales básicas, incluida la de controlar a los esclavos por ley o por pecado ${ }^{9}$. Por otra, el supuesto fundamental de lo político como ámbito, y sin lo cual no se deja entender, es la iniquidad, el pecado, el cual solo puede ser

s.; Rafael Gómez Pérez, La ley eterna en la historia: sociedad y derecho según san Agustín. Eunsa. Pamplona 1972, caps, 2 y 3; Henry Xavier ArQuillière, El agustinismo político. Ensayo sobre la formación de las teorías politicas en la Edad Media. Ed. Universidad de Granada. Granada 2005; Ramiro Flórez, "Los presupuestos del agustinismo político medieval", en Actas del Il Congreso de Filosofía Medieval. Sociedad de Filosofía Medieval. Zaragoza 1996, pp. 11-35.

De civitate Dei, XIX, 17. Cito según la edición de la B.A.C.

De civitate Dei, XIX, 15.

Aparece cierta confusión entre el ámbito político y el ámbito privado (dice que los primeros justos fueron "pastores, no reyes", luego habla del fin de la esclavitud que tendrá lugar con el fin del "principado"); cf. De civitate Dei, XIX, 15. 
comprendido en último término teológicamente. La política se deja así reconducir a la teología. Es la teología la que entrega las respuestas finales a la política.

No obstante, existe para Agustín una cierta autonomía de lo político. En De civitate Dei XIX, 24 define al pueblo como una "congregación de muchas personas, unidas entre sí con la comunión y conformidad de los objetos que ama", con independencia de si esos fines son buenos o malos, justos o injustos.

Sea lo que fuere lo que ama, si es congregación compuesta de muchos, no bestias, sino criaturas racionales, y unidas entre sí con la comunión y concordia de las cosas que ama, sin inconveniente alguno se llamará pueblo.

Es decir, resulta posible concebir a un pueblo cuyo fin sea malo e injusto. Por eso Agustín puede considerar como pueblo al pueblo romano, no obstante su decadencia ${ }^{10}$.

La autonomía respecto de la teología es, sin embargo, solo relativa. Por una parte, la pluralidad fáctica de los fines perseguidos por los diversos pueblos no elimina la posibilidad de calificarlos según los conceptos de bien y mal ${ }^{11}$. Para existir se requiere un mínimo de bondad en el pueblo, sin el cual la concordia desaparece y, en rigor, existirán dos o más pueblos donde había uno; dos o más partidos en pugna ${ }^{12}$.

Las ideas de Agustín guardan bastante semejanza con fundamentaciones del Estado de tipo moderno, como las de Hobbes y Kant. El Estado aparece como una instancia dotada de la capacidad de suspender la guerra de todos contra todos (Hobbes) o la situación de incertidumbre jurídica (Kant), estableciendo un orden de paz según reglas imparciales. El Estado aparece así como un medio de superación de la problematicidad (en Agustín: maldad, pecaminosidad) humana.

\section{El pensamiento político medieval antes de Tomás de Aquino}

Las ideas de Agustín prevalecen en la Cristiandad europea hasta el siglo XIII. Se establece, a partir de sus textos, una tradición que llega

\footnotetext{
Cf. De civitate Dei XIX, 24.

Cf. De civitate Dei XIX, 24.

12 Cf. De civitate Dei XIX, 24. Jorge Martínez Barrera (pp. 38 ss.) indica que la justicia no entraría en el concepto de comunidad política. Habría comunidades políticas injustas, no obstante que funcionales. Esta indicación debe ser tomada con cierta reserva. No obstante que es posible concebir un pueblo injusto, siempre resultará necesario un mínimo de justicia para su existencia. La república de demonios no se sostiene si quienes gobiernan actúan como demonios y vulneran las reglas en beneficio propio a tal punto que ellas pierden sentido.
} 
hasta Alberto Magno, para la cual el origen del poder político radicaría en el pecado ${ }^{13}$.

El acceso al pensamiento de Agustín estuvo más motivado por el interés práctico en la defensa de potestades (especialmente en la época de la reforma gregoriana), que por un interés especulativo. Esta manera de interpretarlo dio lugar a lo que se ha llamado "agustinismo político", el cual ha sido definido por R. P. Mandonnet:

Ausencia de una distinción formal entre el ámbito de la filosofía y el de la teología, es decir, entre el orden de las verdades racionales y el de las verdades reveladas. En ocasiones, ambos órdenes se fusionan para constituir una sabiduría total, partiendo del principio de que las verdades que poseían los antiguos filósofos eran el resultado de una iluminación divina, y que, por tal motivo, formaban parte de la revelación total. En otras ocasiones, los ámbitos de la filosofía y la teología se afirman como siendo distintos de derecho, pero, de hecho, no se llega a fijar un principio capaz de salvaguardar esta distinción. Por otra parte, existe una misma tendencia a borrar la separación formal entre la naturaleza y la gracia. Es este hecho, consistente en la dilución del objeto de la filosofía en el de la teología, el que proporcionó el pretexto, así como una semijustificación a esta queja tan a menudo renovada de que los escolásticos no supieron abordar los problemas científicos independientemente del dogma, e incluso que su filosofía no debe ocupar un lugar en la historia de la ciencia. Pero esta acusación, que tiene un fundamento real para los teólogos agustinianos, ya no tiene razón de ser para la escuela tomista ${ }^{14}$.

La influencia de Aristóteles en la Edad Media es tardía. La obra del Estagirita era prácticamente desconocida en Europa, salvo unos tratados lógicos traducidos por Boecio. Esto no ocurría en el mundo árabe, donde su obra se había difundido y era ampliamente comentada. Recién desde finales del siglo XII, en cambio, Europa comienza a recibir los textos de Aristóteles. Y es en el siglo XIII cuando el discípulo de Alberto Magno, Tomás de Aquino, emprende la interpretación del pensamiento del Estagirita, en un intento por volverlo -hasta donde resulte posible- compatible con la doctrina cristiana ${ }^{15}$. La recepción de Aristóteles no fue asunto pacífico. Su pensamiento presentaba ciertas discrepancias -algunas de ellas graves- con la tradición fundada en Agustín y en Platón. Los textos del Estagirita no se apoyaban en la Revelación, sino que

13. El texto de San Alberto está en: Summa Teologice II Pars, Tract. VI, q. 26, Mb. 1, 1 (Ed. de Lyon).

14 P. MANDonnet, Siger de Brabant et l' Averroïsme latin au XIIIe siècle. Lovaina 1911, pp. 55-56.

15 Cf. H. X. Arquillik̀re, El agustinismo político, p. 36. 
en una observación relativamente autónoma de los diversos objetos de estudio. La Política es un buen ejemplo de esta autonomía (Aristóteles estudia no solo el buen gobierno, sino también el mejor posible para ciudadanos imperfectos).

Estas discrepancias motivaron diversas reacciones. Por una parte, la de los seguidores de Averroes, que conformaron el denominado "averroísmo latino"; por otra, la de quienes rechazaban las obras aristotélicas por considerarlas contrarias a la fe cristiana (aquí se ubican los más cercanos al agustinismo). También hubo quienes destacaron el énfasis empírico e investigativo de la obra del Estagirita (en Oxford, p. ej. Rogelio Bacon $)^{16}$. En fin, está aquella posición que vio en Aristóteles a un filósofo altamente relevante, de cuya obra no se podía simplemente prescindir, sino que, al contrario, debía ser incorporada dentro del pensamiento cristiano. Alberto Magno fue quien comenzó a estudiar y comentar sus obras. Sus comentarios son críticos y no una mera aceptación de lo expuesto ${ }^{17}$. Le continuó su discípulo, Tomás de Aquino. Fue el Aquinate quien incorporó a la filosofía cristiana de manera sistemática los principios contenidos en la obra aristotélica.

Por lo que respecta a la Política de Aristóteles, donde se contempla la fundamentación de la polis que Tomás de Aquino recoge, no existen datos concretos que hablen de un conocimiento de ese texto en el mundo árabe ${ }^{18}$. En Europa se volvió conocida solo con la traducción de Guillermo de Moerbeke, alrededor de $1260^{19}$. El primer comentario de esta obra es de Alberto Magno. Luego la comentó también Tomás de Aquino. En lo que sigue nos detendremos en el comentario, así como en otros textos, donde el Aquinate formula principios políticos que se apoyan de alguna manera en el texto del Estagirita.

\section{LA COMPLEMENTACIÓN TOMISTA DE LA FUNDAMENTACIÓN NEGA- TIVA DE LA UNIDAD POLÍTICA Y LAS POSIBILIDADES DE FORTALE- CIMIENTO DE ESA UNIDAD POLÍTICA QUE DE AHí SE SIGUEN}

Son las interpretaciones que de la obra de Aristóteles realiza Tomás de Aquino las que vienen a alterar la predominancia del pensamiento

16 Cf. Etienne GILson, La Filosofía en la Edad Media: desde los orígenes patristicos hasta el fin del siglo XIV. Gredos. Madrid 1976; Julius WeINBERG, Breve bistoria de la filosofía medieval. Cátedra. Madrid 1987.

17 Cf. Ingrid Craemer-Ruegenberg, Alberto Magno. Herder. Barcelona 1985.

t8 Cf. José Puig, "Nota sobre política e Islam en Averroes", en: Actas del II congreso nacional de filosofía medieval. Sociedad de Filosofía medieval. Zaragoza, 1996, pp. 291 ss.

19 Cf. Jean Dunbabin, "The reception and interpretation of Aristotle's Politics", en: Norman KretZMann y otros, The Cambridge History of Later Medieval Pbilosophy. Cambridge University Press 1982, p. 723. 
inspirado en Agustín. A partir de esas interpretaciones cambia, si no la manera de justificar la unidad política, al menos el énfasis con que se marcan los distintos momentos de esa fundamentación.

Aristóteles había sostenido una cierta autonomía de lo político respecto de lo teológico. Su fundamentación o justificación de la polis o unidad política no se orientaba teológicamente, no se acudía a un principio como el pecado original. Tampoco pretendía Aristóteles fundarla exclusivamente en una situación de precariedad y de posibilidad de abusos por parte de otros más fuertes. Debe destacarse, no obstante, que la justificación "negativa" del Estado o unidad política como superación de la situación de necesidad y de la problematicidad humana no era desconocida para el Estagirita: "Privado de ley y derecho" el ser humano es, indica: "la peor de las criaturas" ${ }^{20}$. En la Retórica plantea:

Por regla general los bombres cometen injusticia cuando tienen el poder para ello ${ }^{21}$.

\section{Y en la Política:}

Quien por naturaleza y no solo por casualidad vive fuera de la polis, o es peor o es mejor que un ser bumano $0^{22}$.

Es en la polis donde, mediante un orden jurídico apoyado por la fuerza, la fuerza desordenada puede ser controlada.

Aristóteles reconoce también que la polis incorpora dentro de sus fines la satisfacción de lo necesario para la vida. La polis, no obstante que está hecha para vivir bien, nace por las necesidades de la vida, por la debilidad y precariedad del ser humano frente a su medio natural ${ }^{23}$. El individuo no se basta a sí mismo y debe comportarse respecto de la polis como una parte respecto del todo ${ }^{24}$. Quien no requiere de la comunidad porque se basta a sí mismo, no es humano, sino o bien un animal o bien un $\operatorname{dios}^{25}$.

Sin embargo, Aristóteles no se queda ahí, y señala explícitamente que la polis tiene como fin no solo la vida, sino la vida buena ${ }^{26}$, es decir, la vida feliz, que en la Política coincide con la vida conforme a la virtud. Es en la polis donde las capacidades humanas podrán alcanzar

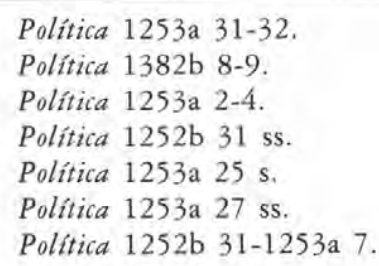


su máximo despliegue. Aristóteles ejemplifica esto con la capacidad humana del lenguaje ${ }^{27}$. Esta capacidad la desarrolla el ser humano solo en relación con otros y más perfectamente en la comunidad más perfecta, esto es, en la polis.

La naturaleza no hace nada en vano, como decimos. Abora bien, de entre todos los seres animales solo el hombre está dotado de lenguaje. El sonido es la señal de dolor y placer y por ello les es otorgada también a otros seres sensibles, pues su naturaleza se despliega hasta un punto tal que pueden percibir placer y dolor y dar a conocerlos. La palabra, sin embargo, o el lenguaje, están para mostrar lo útil y lo dañino, lo justo y lo injusto y lo que les es semejante. La comunitariedad de estas ideas fundamenta la familia y la polis ${ }^{28}$.

Estas ideas son recogidas por el Aquinate, lo que las vuelve disponibles para Occidente, de tal manera que A. Black puede llegar a sostener la imposibilidad de entender el pensamiento político moderno sin el correcto estudio de la interpetación de Aristóteles durante los últimos siglos de la Edad Media ${ }^{29}$.

Tomás reconoce que la comunidad política tiene como fin lo necesario para la vida ${ }^{30}$, así como el establecimiento de un orden de paz capaz de poner coto a las tendencias humanas gravemente contrarias al despliegue humano ${ }^{31}$. Sin embargo, junto a esto, Tomás comparte con Aristóteles el reconocimiento de la unidad política como aquella en donde el ser humano puede alcanzar una vida buena ${ }^{32}$. Ocupa el mismo ejemplo de Aristóteles, el lenguaje ${ }^{33}$.

Tomás complementa los argumentos del Estagirita con reflexiones de carácter teológico. Se podría decir, enfatizando un poco, que, a diferencia de Agustín, que "teologiza" la política para luego, en la vida sin pecado, despolitizar la teología, Tomás, junto con otorgarle autonomía a lo político respecto de lo teológico, "politiza" en cierto sentido la vida sin pecado. Indica que aun en la situación previa al pecado, el gobierno político ha de existir. El Aquinate toma posición respecto de la teoría de Agustín, según la cual el gobierno de unos hombres sobre otros es consecuencia del pecado. Distingue, al igual que Aristóteles, entre el

Politica 1253a 13-19.

Política 1253 a $7-19$.

Cf. Anthony BLACK, El pensamiento politico en Europa, 1250-1450. Cambridge University Press 1996, pp. 30 y ss.

De Regno I, 1, 449, 28-38.

Sentencia Libri Etbicorum 4, 55-78 (cit. según la ed. leonina, t. XLVII, Roma 1969).

De Regno II, 3, 466, 64-73 (seguimos la ed. de Tecnos. Madrid 1995); Suma contra gentiles III, 128 (seguimos la ed. de la B.A.C., Madrid 1967).

33

De Regno I, 1, 450, 56-64. 
dominio sobre siervos y el gobierno sobre libres. El primero lo entiende -al igual que Agustín- como consecuencia del pecado. Sin embargo, el segundo no sería consecuencia del pecado y existiría aún en el estado de inocencia. Solo este último tipo de dominio sería propiamente político, es decir, se ordenaría a un bien común a gobernantes y gobernados. El Aquinate argumenta para mostrar cómo este gobierno existiría aún en el estado de inocencia a partir de la naturaleza social del ser humano. La vida social requiere de uno que oriente a los individuos hacia el bien común, pues la multitud, indica, tiende por sí a muchas $\operatorname{cosas}^{34}$.

La recepción tomista de la obra de Aristóteles permite complementar el énfasis agustiniano en la iniquidad y la necesidad como orígenes de principados y potestades, con la idea de una unidad política que posibilita el despliegue de capacidades humanas fundamentales (lenguaje, virtudes) y la realización de una vida buena. El solo temor al castigo, sea humano o divino, lo mismo que al estado de necesidad material o de inseguridad jurídica no bastan para mantener unida a la polis en la crisis. Cuando la crisis es tal que ya "no conviene" defender la propia unidad política, porque los costos materiales parecen mayores que los beneficios esperados, entonces el Estado seguirá existiendo solo cuando exista entre los miembros de la unidad política respectiva una amistad política, fundada sobre lo necesario y lo útil, pero, fundamentalmente, también sobre lo justo y lo bueno, es decir, sobre verdades que encarnen y constituyan lo que Carl Schmitt ha llamado una "manera de existir" 35 .

Eso por lo que toca a la explicación del fenómeno "unidad política" en la crisis. Por lo que respecta ahora a la justificación general de la unidad política o Estado, la contribución de Aristóteles y Tomás de Aquino es altamente provechosa para la reflexión política posterior. Y es que la unidad política puede contribuir al despliegue de aspectos humanos fundamentales: al desarrollo de virtudes éticas e intelectuales. Diversos autores han llamado la atención sobre el inmenso acervo cultural con el que nos pone en contacto el pertenecer a una unidad política más o menos desarrollada. ${ }^{36} \mathrm{Y}$ son múltiples las maneras en las que la

\footnotetext{
34 Cf. S. Th. I, q. 96, a. 4c; q. 92, a. 4ad2. Sobre la disputa Tomás-Agustín, cf. D. Sternberger, "Der alte Streit um den Ursprung der Herrschaft", pp. 23 s.

35 Cf. C. Sснмiтt, Der Begriff des Politischen. Hamburgo 1933, p. 8; Berlín 1963, pp. 27, 35 , 55, 94 s.; Theorie des Partisanen. Zwischenbemerkung zum Begriff des Politischen. Berlin 1995 $\left({ }^{1} 1963\right)$, p. 87; Hugo Herrera, Sein und Staat. Die ontologische Begriindung der politischen Praxis bei Helmut Kubn. Königshausen \& Neumann. Würzburg 2005, capítulo 4; también: H. Herrera, "Das Denken Carl Schmitt und die 'klassische' politische Philosophie", en: Staat und Politik. Nomos. Baden-Baden 2003.

36 Cf. Paul-Ludwig Weinacht, "Nation als Integral moderner Gesellschaft", en: J. Gebhardt/R. Schmalz-Bruns (ed.), Demokratie, Verfassung und Nation. Die politische Integration moderner Gesellschaften. Baden-Baden 1994; Donate KLUXEN-PYTA, Nation und Ethos. Die Moral des Patriotismus. Freiburg/München 1991.
} 
unidad política puede contribuir al despliegue de las virtudes humanas (p. ej., apoyando el establecimiento y mantenimiento de escuelas).

\section{Justificación “positiva” y Libertad}

Una objeción atendible a la justificación "positiva" del Estado o unidad política es la que formulara una vez Kant frente a la amenaza despótica, y que hoy, en la época del desarrollo tecnológico, es formulable contra el riesgo totalitario: cuando el Estado se orienta a la felicidad, "el soberano quiere hacer feliz a su pueblo según sus propias ideas y se vuelve déspota; el pueblo no se querrá dejar quitar la pretensión humana general hacia la propia felicidad y se volverá rebelde" 37 .

Kant propone que el Estado se restrinja a garantizar la libertad mediante el establecimiento de un orden jurídico. Ese orden jurídico o derecho es un concepto puro de la razón, vale decir, cuya validez no depende de la experiencia. Lo define como:

La encarnación de las condiciones bajo las cuales el capricho de uno puede ser unificado con el capricho de otro, según una ley general de la libertad ${ }^{38}$.

Ese es el fin del Estado y ese el criterio fundamental al cual debiera ajustarse. Si no respeta ese criterio por defecto, es decir, porque ni siquiera esa regla mínima es atendida, se cae en el capricho injustificado, que ya no es derecho, sino incertidumbre jurídica; ya no hay Estado, sino que se cae en formas de agrupación en las que hay fuerza, pero orientada a fines caprichosos. $\mathrm{Si}$, en cambio, se vulnera ese criterio y fin por exceso, esto es, porque se busca un fin máximo, se cae en el capricho despótico o totalitario. La realización del derecho sería, para Kant, posible, aún en un Estado de demonios, es decir, de individuos preocupados de satisfacer su capricho egoísta. La única condición es que posean entendimiento, esto es, la capacidad de realizar cálculos de costos y beneficios ${ }^{39}$.

37 I. KANT, "Über den Gemeinspruch: Das mag in der Theorie richtig sein, taugt aber nicht für die Praxis", en: Akademieausgabe, tomo VIII, p. 302.

38 I. Kant, "Metaphysische Anfangsgründe der Rechtslehre", en: Akademieausgabe, tomo VI, \& B.

39 Immanuel Kant, Vom Ewigen Frieden. Ed. Karl Vorländer. Leipzig 1919, Segundo artículo definitivo, p. 18. Kant habla de la posibilidad efectiva de que resulte dirigir las fuerzas de los ciudadanos ambiciosos "de tal manera que una detenga a las otras en su efecto destructivo o la suspenda: de modo que el éxito para la razón opera como si ambas no estuviesen ahí, y así el ser humano es obligado a ser un buen ciudadano, aun cuando no sea un hombre moralmente bueno"; Primer anexo, pp. $31 \mathrm{~s}$. 
La posición antidespótica -o antitotalitaria- de Kant es atendible, en cuanto advierte contra los excesos en que puede incurrir un poder político afanado en hacer directamente felices a sus súbditos. Ella es una de las bases fundamentales del moderno liberalismo político. Sin embargo, presenta dos problemas fundamentales.

El primero de ellos es que el sistema que describe no es capaz de funcionar por sí solo. Es posible concebir un Estado que funcione, en el cual los súbditos sean individuos egoístas calculadores, "demonios", como dice Kant. Sin embargo, no es posible concebir un Estado que funcione donde todos, súbditos y gobernantes, policía, legisladores y tribunales incluidos, sean demonios. Pues si los detentadores del poder no se preocupan por la generalidad, sino que solo del interés propio, y si no tratan a los demás también como fines en sí mismos, sino solo como medios, como instrumentos, entonces el orden jurídico y político degenerará en un sistema de abusos de los poderosos sobre los débiles: se regresa, en definitiva, a la situación ajurídica o de incertidumbre y capricho previa al establecimiento del derecho ${ }^{40}$. La orientación al bien de la generalidad no es posible establecerla, respecto de los detentadores del poder, mediante mecanismos institucionales, hay un momento en el que la institucionalidad fracasa: en relación de los que la pueden manejar. Aquí, la orientación al bien común solo puede ser lograda de manera estable, mediante gobernantes virtuosos, o al menos no gravemente viciosos.

Esto nos lleva a una segunda debilidad del planteamiento kantiano. No obstante que el Estado kantiano pudiese funcionar (lo que, según hemos mostrado, resulta altamente problemático), al reducir Kant la convivencia estatal a un mero tráfico externo entre individuos aislados, deja de lado la relevancia del carácter comunitario y político-comunitario del ser humano. Si ese carácter es dejado de lado, si el modelo político ya no es el de una comunidad preocupada por sus miembros, sino que un conjunto de individuos vinculados por reglas de tráfico social, se pierde o debilita un aspecto relevante para el despliegue y la felicidad humana. Para el despliegue de capacidades intelectuales, como el lenguaje (cuya ampliación tiene que ver con la existencia de una vida comunitaria desarrollada), pero también afectivas, las que se adquieren preferentemente en comunidades como la familia, la amistad, las iglesias, la nación (las que requieren, para subsistir, del marco y del apoyo otorgados por el Estado). En estas comunidades los vínculos de utilidad,

40 Esta crítica es extensible también a la autonomización que Agustín emprende respecto de lo político, cuando afirma que hay pueblo aún si lo que él ama es malo: en rigor no es posible que una unidad política exista si el pueblo no ama un mínimo de justicia y si los que, de ese pueblo, ejercen el poder no actúan también según un mínimo de justicia. Si la actitud del pueblo y los gobernantes es siempre caprichosa y egoísta, se acaba el Estado político y la comunidad desaparece. 
en donde el otro es puro medio, pueden ser relativizados por relaciones en donde lo buscado es también el bien del otro y de la comunidad. Sin el apoyo del Estado o mediante intervención estatal en sus órdenes propios, estas comunidades se debilitan. Ellas requieren de un cuidado político que las respete y apoye en su especificidad como formas de relación. La concepción kantiana del fin del Estado se desentiende de ese cuidado y, con ello, termina por contribuir a su debilitamiento.

Sin cuidado estatal, con el debilitamiento de las comunidades, se dificultará el surgimiento, en los súbditos y en los gobernantes, de algo así como un sano patriotismo y la preocupación por los demás y por la totalidad nacional.

¿Hay, sin embargo, una "tercera vía", una alternativa distinta a totalitarismo o a la inseguridad del capricho individual? Es posible afirmarla. Y de alguna manera está ya dicho en los textos de Aristóteles y Tomás: la familia, la aldea y en Tomás además la Iglesia, son agrupaciones irreductibles a la polis. Es por eso, precisamente, que Aristóteles rechaza la idea platónica de una comunidad de hijos entre los guardianes: es preferible un primo de carne y hueso que un "hermano" de los que Platón considera en su República ${ }^{41}$. Por eso también rechaza la comunidad de bienes propuesta por Platón ${ }^{42}$. La unidad política vive de una vitalidad que no puede generar, aunque sí corromper, por descuido o intervencionismo: una vitalidad que florece en las agrupaciones que surgen entre el individuo y el Estado, especialmente en las que se encuentran dotadas de carácter comunitario ${ }^{43}$, pues es en ellas donde mejor surge la amistad. El adecuado cuidado de esas comunidades exige tanto apoyarlas como garantizar su autonomía, dentro del ámbito de sus fines naturales. La explicación detallada de este cuidado es tarea extensa, que excede las páginas de este artículo. Aquí llegamos a indicar la posible salida al problema planteado por un Estado tambaleante entre el capricho privado y el capricho del déspota.

\section{Bibliografía CONSUlTADA}

- Agustin de Hipona: De civitate Dei, XIX, edición de B.A.C.

- ARistóteles: Política.

- Arquillière, Henry Xavier: El agustinismo político. Ensayo sobre la formación de las teorías políticas en la Edad Media, Ed. Universidad de Granada, Granada, 2005.

\footnotetext{
41 Política 1262 a 14.

42 Política 1262 b 36 ss.

43 Para el concepto de comunidad: cf. Ferdinand TönNIEs, Gemeinschaft und Gesellschaft. Grundbegriffe der reinen Soziologie, Darmstadt 1963, pp. 3 ss., 8 ss., 40 ss.
} 
- Bakunin, Michael: Prinzipien und Organisation der Internationalen Revolutionären Gesellschaft, en: Gesammelte Werke, Berlín, 1975, Tomo III.

- Black, Anthony: El pensamiento político en Europa, 1250-1450, Cambridge University Press, 1996.

- Craemer-Ruegenberg, Ingrid: Alberto Magno, Herder, Barcelona, 1985.

- Diefenbacher, Hans: Anarchismus-die verlorene Utopie?, en: H. Diefenbacher (ed.): Anarchismus. Zur Geschichte und Idee der berrschaftsfreien Gesellschaft, Darmstadt, 1996.

- Dunbabin, Jean: "The reception and interpretation of Aristotle's Politics", en: Norman Kretzmann y otros, The Cambridge History of Later Medieval Philosophy, Cambridge University Press, 1982.

- Flórez, Ramiro: "Los presupuestos del agustinismo político medieval", en Actas del II Congreso de Filosofía Medieval, Sociedad de Filosofía Medieval, Zaragoza, 1996.

- Gilson, Etienne: La Filosofía en la Edad Media: desde los orígenes patrísticos hasta el fin del siglo XIV. Gredos. Madrid 1976.

- Gómez Pérez, Rafael: La ley eterna en la historia: sociedad y derecho según san Agustín, Eunsa, Pamplona, 1972.

- Herrera, Hugo: Sein und Staat. Die ontologische Begründung der politischen Praxis bei Helmut Kubn, Königshausen \& Neumann, Würzburg, 2005.

: "Das Denken Carl Schmitt und die 'klassische' politische Philosophie", en: Staat und Politik, Nomos, Baden-Baden, 2003.

- Kant, I.: "Über den Gemeinspruch: Das mag in der Theorie richtig sein, taugt aber nicht für die Praxis", en: Akademieausgabe, tomo VIII.

- ___ " Metaphysische Anfangsgründe der Rechtslehre", en: Akademieausgabe, tomo VI, § B.

: Vom Ewigen Frieden, Ed. Karl Vorländer, Leipzig, 1919.

- Kluxen-Pyta, Donate: Nation und Ethos. Die Moral des Patriotismus, Freiburg/München, 1991.

- Lösche, Peter: Anarchismus, Darmstadt, 1977

- MANDONnET, P.: Siger de Brabant et l'Averroïsme latin au XIIIe siècle, Lovaina, 1911.

- MarX, Karl/Friedrich Engels: Werke, ed. por Hans-Joachim Lieber y otros, Stuttgart/Darmstadt 1962, Tomo II.

- Puig, José: "Nota sobre política e Islam en Averroes", en: Actas del II congreso nacional de filosofía medieval, Sociedad de Filosofía medieval, Zaragoza, 1996.

- Sternberger, D.: "Der alte Streit um den Ursprung der Herrschaft" (1977), en: D. Sternberger, Schriften III. Frankfurt a. M., 1980. 
- Tomás de Aquino: Summa Teologia, II Pars, Tract. VI, q. 26, Mb. 1,1 Ed. de Lyon.

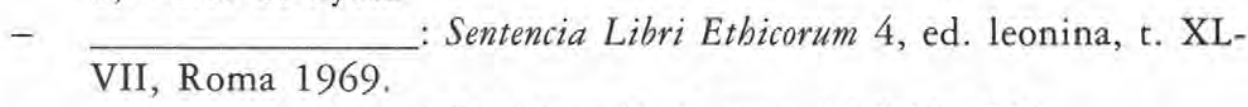

- $\quad$ _ De Regno II, Tecnos. Madrid 1995.

- _ Suma contra gentiles III, B.A.C., Madrid 1967.

- Tönnies, Ferdinand: Gemeinschaft und Gesellschaft. Grundbegriffe der reinen Soziologie. Darmstadt 1963.

- Schmitt, C.: Der Begriff des Politischen, Hamburgo, 1933; Berlín 1963.

- $\quad$ : Theorie des Partisanen. Zwischenbemerkung zum Begriff des Politischen, Berlin, 1995 (1963).

- Weinacht, Paul-Ludwig: "Nation als Integral moderner Gesellschaft”, en: J. Gebhardt/R. Schmalz-Bruns (ed.), Demokratie, Verfassung und Nation. Die politische Integration moderner Gesellschaften. Baden-Baden, 1994.

- Weinberg, Julius: Breve bistoria de la filosofía medieval, Cátedra, Madrid, 1987. 